\title{
Spinal cord stimulation for chronic pain management: mini-review
}

\author{
Younghoon Jeon \\ Department of Anesthesiology and Pain Medicine, Kyungpook National University Hospital, School of Dentistry, Kyungpook National \\ University, Daegu, Korea
}

Received September 30, 2017

Revised November 24, 2017

Accepted December 1, 2017

Corresponding author

Younghoon Jeon

Department of Anesthesiology

and Pain Medicine, Kyungpook

National University Hospital, School

of Dentistry, Kyungpook National

University, 130 Dongdeok-ro, Jung-

gu, Daegu 41944, Korea

Tel: +82-53-429-5871

Fax: +82-53-426-2760

E-mail: jeon68@gmail.com
Spinal cord stimulation (SCS) has been used extensively for the management of refractory chronic pain, including complex regional pain syndrome and failed back surgery syndrome. The progressive improvements in the selection criteria of patients, implantation devices, and techniques in implantation can lead to satisfactory results for the treatment of a range of chronic pain. In addition, despite its high initial cost, it provides an improvement of the function and quality of life of patients cost-effectively, compared to alternative therapy strategies. This article reviews the equipment and technology, indications, and complications of SCS.

Keywords: Complex regional pain syndromes; Failed back surgery syndrome; Spinal cord stimulation

\section{INTRODUCTION}

Shealy et al. [1] introduced the concept of dorsal column stimulation by implanting an electrode lead into the epidural space. In 1967, he implanted a dorsal column stimulator into the epidural space in patients suffering from cancer pain. Recently, it was demonstrated that many spinal neural structures (dorsal columns, dorsal roots, dorsal root entry zone and the dorsal horn) were stimulated by the electrical stimulation of the lead in the epidural space [2]. The mechanism of the analgesic action of spinal cord stimulation (SCS) was based initially on the gate control theory of pain proposed by Melzack and Wall [3]. On the other hand, it has been suggested that the SCS has multiple analgesic actions by acting on any abnormal activity in the A- $\beta$ neurons that receive pain, restoring the normal gamma amino butyric acid levels in the dorsal horn, and releasing adenosine in the central nervous system $[4,5]$. In the spinal cord, pain modulating neurotransmitters, such as substance-P, and serotonin, are released by SCS [G. In addition, SCS interferes with the direct transmission of pain signals traveling along the spinal cord to the brain [7]. At low levels of stimulation, the activity of the sympathetic nerve system was attenuated significantly, resulting in a reduction of pain and an increase in blood flow $[7,8]$.

In 2017, Farber et al. [9] included 5,328 patients who underwent SCS implantation for the treatment of failed back surgery syndrome (FBSS) and found that SCS provided long

This is an Open Access article distributed under the terms of the Creative Commons Attribution Non-Commercial License (http://creativecommons.org/licenses/by-nc/4.0) which permits unrestricted noncommercial use, distribution, and reproduction in any medium, provided the original work is properly cited. Copyright $($ Medical Biological Science and Engineering. 
term cost effectiveness despite the high initial cost compared to conventional medical management (CMM). In a previous study, the health-related quality of life (HRQoL) and the cost implications of SCS combined with CMM was compared with CMM alone in 100 patients with FBSS. The SCS required additional healthcare cost but greatly improved the HRQoL [10].

\section{THE EQUIPMENT AND TECHNOLOGY}

The SCS system includes the electrode leads, a cable, a pulse generator, and a programmer. The unipolar electrodes were initially introduced, which can produce a limited field of paresthesia and allow the application of leads. Electrode leads with four to ten electrodes were subsequently developed to stimulate multiple dermatomes of pain. The percutaneous electrode can be implanted into the epidural space via Tuohy needles without a laminectomy (Fig. 1). The percutaneous technique can be ideal because it allows the placement of SCS without a surgical incision [11]. In addition, a percutaneous technique allows the testing of several spinal cord levels. By placing multiple parallel electrodes into the epidural space, various configuration matrices can be constructed to stimulate painful dermatomes. On the other hand, a paddle electrode lead can be placed in the epidural space via open surgery (laminotomy or partial laminectomy), which provides greater stability and less predisposition to migrate [11,12].

The implanted leads are connected to the pulse generator via an extension cable. The pulse generator contains a

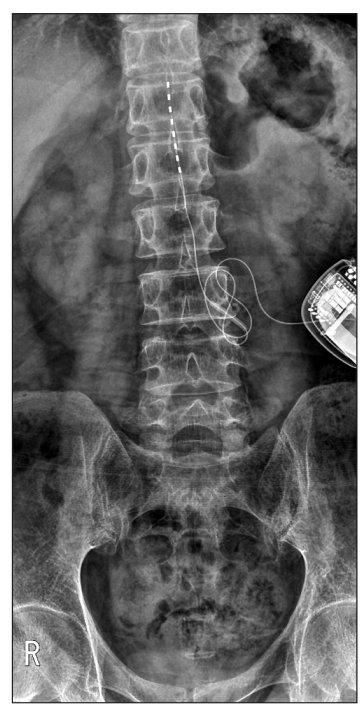

Fig. 1. Implantation of the percutaneous spinal cord stimulator. lithium battery, which is activated and managed by adjusting the amplitude, pulse width, and frequency using outside telemetry [13]. Patients alone can turn the stimulator on and off, and control the stimulation amplitude, frequency, and pulse width. The lifespan of the battery varies manly with the use and the level of utilized parameters (voltage, rate, pulse width, etc.). With the average use, most patients implanted with non-rechargeable pulse generators can expect a battery life of 2.5 and 4.5 years [13]. On the other hand, a new SCS system with a rechargeable pulse generator can last for up to 10 years [13]. In addition, it is suitable for patients requiring higher amplitudes of stimulation. Recently, the rechargeable pulse generator has been used widely because of its small size and ease of maintenance [14,15].

\section{INDICATIONS}

Neuropathic pain is sometimes refractory to current pharmacological treatments and nerve blocks. Spinal neuromodulation is one of the most exciting developments in the pain management. SCS is effective in the treatment of intractable neuropathic pain disorders (Table 1).

\section{Failed back surgery syndrome}

FBSS is defined as a condition of persistent pain after back surgery. SCS is effective in the treatment of pain in the upper and lower extremities while the effectiveness of SCS in axial pain is controversial $[16,17]$. A meta-analysis conducted by Taylor et al. [18] showed that SCS not only reduces pain, but also improves the quality of life by decreasing the consumption of analgesics over time. In this study, the level of evidence for the efficacy of SCS in FBSS was "moderate." In 1991, North et al. [19] examined the effects of SCS in 50 patients with FBSS (averaging 3.1 previous operations). They recorded at least $50 \%$ sustained pain reduction in $53 \%$ of patients at 2.2 years and in $47 \%$ of patients at 5.0 years after the implantation of SCS. In addition, most patients reported significant improvements in their activities of daily living, and

Table 1. Indications for spinal cord stimulation

Failed back surgery syndrome

Complex regional pain syndrome (type 1 and 2)

Neuropathic pain secondary to peripheral nerve injury

Post herpetic neuralgia

Post amputation phantom limb pain 
10 out of 40 patients who were disabled prior to SCS returned to work. In 2005, North et al. [20] compared the efficacy of SCS and re-operation for the management of refractory FBSS with radicular neuropathic pain (with or without low back pain). SCS was more successful with greater than $50 \%$ pain reduction than reoperation after a 3 year follow up. In addition, the amount of opiate analgesics decreased significantly in SCS compared to re-operation [20]. Kumar et al. [21] reported that SCS was superior to CMM in patients with FBSS after a 24 month follow-up. They also showed that SCS improved significantly the leg pain relief, HRQoL, and functional capacity [21].

\section{Complex regional pain syndrome}

Complex regional pain syndrome (CRPS), formerly known as reflex sympathetic dystrophy, is a chronic pain syndrome that often progresses with time. This pain is a type of neuropathic pain with a variety of symptoms, including spontaneous pain, allodynia, hyperalgesia, dystrophic changes in the skin, osteoporosis, and loss of motor functions [22]. Broseta et al. [23] reported that the pain associated with nerve injuries or amputation was decreased significantly in all patients who received SCS. In 2004, Kemler et al. [24] examined the effects of SCS with physiotherapy compared to physical therapy alone in patients with CRPS type I. They reported that at the 6 month follow-up, the mean decrease in pain score was 2.4 with SCS compared to 0.4 with physical therapy using the visual analog scale (VAS) from 0 (no pain) to 10 (worst possible pain). In addition, patients with SCS showed significant improvement in the pain-rating index, McGill Pain Questionnaire, and the HRQoL [24]. On the other hand, Kemler et al. [25] reported that the painalleviating effects of SCS in patients with CRPS-I decreased over time, and produced results similar to those of physical treatment. Despite this, the global perceived effect of SCS was higher in that of physical treatment, and $95 \%$ of patients with SCS would repeat the SCS treatment [25]. Some studies suggested that SCS should be included in the guidelines for the management of CRPS [26-28]. If patients do not respond to conventional treatments within 12 to 16 weeks, a trial of SCS is recommended for patients diagnosed with CRPS that is refractory to treatment, such as medication and nerve block within 3 months [28].

\section{Post herpetic neuralgia}

The effectiveness of SCS for the treatment of post herpetic neuralgia (PHN) is controversial. Recently, it was reported that SCS resulted in excellent pain reduction in 23 out of 28 patients (82\%) with intractable PHN [29]. In addition, it was found that SCS may be considered as an effective option for patients with refractory pain during the acute and sub-acute phases of herpes zoster [30]. Further studies will be needed to evaluate the efficacy of SCS for the prevention or treatment of PHN.

\section{COMPLICATIONS}

Patients reported several complications related to SCS, which resulted in an increase in medical cost and a decrease in the effect of SCS (Table 2). The rate of complications associated with SCS was reported to be $20 \%$ to $40 \%$ [11,31]. The complications were generally minor with the proper expertise. The most common complication was electrode migration ( $11 \%$ to $45 \%$ ). The incidence of migration of the electrode lead was reported to be higher in a percutaneous lead than paddle leads. The migration of the lead generally occurred within 1 week after the implantation of SCS. The neurological complications due to a spinal nerve injury, epidural hematoma, and infection can be fatal [32]. Strict sterilization and prophylactic antibiotic therapy should be considered during the procedure [16]. Local pain at the implant site should be investigated for an indolent infection of the implanted equipment. When infection occurs, antibiotics and the removal of the infected hardware are required [32]. Persistent pain at the insertion of a battery can sometimes require repositioning of the battery. The incidental leakage of cerebral spinal fluid during the procedure can cause a postdural puncture headache, which requires conservative management or epidural blood patch [14].

Table 2. Complications related to spinal cord stimulation

Electrode migration
Infection
Postdural puncture headache
Local pain
Hardware malfunction

Electrode migration

Postdural puncture headache

Hardware malfunction 


\section{CONCLUSION}

Chronic and intractable pain should be considered as a disease entity. SCS has been well established as an effective treatment for several pain conditions. SCS has been proven to be effective in the long term for chronic intractable pain conditions. In addition, SCS improve the functional ability and quality of life. To increase the effectiveness of SCS, suitable patients should be selected, and the physician should be aware of the anatomy and physiology of the spinal cord and master the technique for the implantation of SCS.

\section{CONFLICT OF INTEREST}

No potential conflict of interest relevant to this article was reported.

\section{REFERENCES}

1. Shealy CN, Mortimer JT, Reswick JB. Electrical inhibition of pain by stimulation of the dorsal columns: preliminary clinical report. Anesth Analg 1967;46:489-91.

2. Barolat G. Epidural spinal cord stimulation: anatomical and electrical properties of the intraspinal structures relevant to spinal cord stimulation and clinical correlations. Neuromodulation 1998;1:63-71.

3. Melzack R, Wall PD. Pain mechanisms: a new theory. Science 1965;150:971-9.

4. Meyerson BA, Ren B, Herregodts P, Linderoth B. Spinal cord stimulation in animal models of mononeuropathy: effects on the withdrawal response and the flexor reflex. Pain 1995;61: 229-43.

5. Larson SJ, Sances A Jr, Riegel DH, Meyer GA, Dallmann DE, Swiontek T. Neurophysiological effects of dorsal column stimulation in man and monkey. J Neurosurg 1974;41:217-23.

6. Bantli H, Bloedel JR, Thienprasit P. Supraspinal interactions resulting from experimental dorsal column stimulation. J Neurosurg 1975;42:296-300.

7. Oakley JC, Prager JP. Spinal cord stimulation: mechanisms of action. Spine (Phila Pa 1976) 2002;27:2574-83.

8. Linderoth B. Spinal cord stimulation in ischemia and ischemic pain: possible mechanisms of action. In: Horsch S, Claeys L, editors. Spinal cord stimulation II: an innovative method in the treatment of PVD and angina. Heidelberg: Steinkopff-Verlag Darmstadt; 1995. p. 19-35.

9. Farber SH, Han JL, Elsamadicy AA, Hussaini Q, Yang S, Pagadala P, et al. Long-term cost utility of spinal cord stimulation in patients with failed back surgery syndrome. Pain
Physician 2017;20:E797-805.

10. Manca A, Kumar K, Taylor RS, Jacques L, Eldabe S, Meglio M, et al. Quality of life, resource consumption and costs of spinal cord stimulation versus conventional medical management in neuropathic pain patients with failed back surgery syndrome (PROCESS trial). Eur J Pain 2008;12:1047-58.

11. Mekhail NA, Mathews M, Nageeb F, Guirguis M, Mekhail MN, Cheng J. Retrospective review of 707 cases of spinal cord stimulation: indications and complications. Pain Pract 2011;11: 148-53.

12. Lee AW, Pilitsis JG. Spinal cord stimulation: indications and outcomes. Neurosurg Focus 2006;21:E3.

13. Baranidharan G, Titterington J. Recent advances in spinal cord stimulation for pain treatment. Pain Manag 2016;6:581-9.

14. Barolat G. Spinal cord stimulation for chronic pain management. Arch Med Res 2000;31:258-62.

15. Bir SC, Konar S, Maiti T, Nanda A, Guthikonda B. Neuromodulation in intractable pain management: outcomes and predictors of revisions of spinal cord stimulators. Neurosurg Focus 2016;40:E4.

16. Bedder MD, Bedder HF. Spinal cord stimulation surgical technique for the nonsurgically trained. Neuromodulation 2009;12 Suppl 1:1-19.

17. Chincholkar M, Eldabe S, Strachan R, Brookes M, Garner F, Chadwick $R$, et al. Prospective analysis of the trial period for spinal cord stimulation treatment for chronic pain. Neuromodulation 2011;14:523-8.

18. Taylor RS, Van Buyten JP, Buchser E. Spinal cord stimulation for chronic back and leg pain and failed back surgery syndrome: a systematic review and analysis of prognostic factors. Spine (Phila Pa 1976) 2005;30:152-60.

19. North RB, Ewend MG, Lawton MT, Kidd DH, Piantadosi S. Failed back surgery syndrome: 5-year follow-up after spinal cord stimulator implantation. Neurosurgery 1991;28:692-9.

20. North RB, Kidd DH, Farrokhi F, Piantadosi SA. Spinal cord stimulation versus repeated lumbosacral spine surgery for chronic pain: a randomized, controlled trial. Neurosurgery 2005;56:98-106.

21. Kumar K, Taylor RS, Jacques L, Eldabe S, Meglio M, Molet J, et al. Spinal cord stimulation versus conventional medical management for neuropathic pain: a multicentre randomised controlled trial in patients with failed back surgery syndrome. Pain 2007;132:179-88.

22. Abu-Arafeh H, Abu-Arafeh I. Complex regional pain syndrome in children: a systematic review of clinical features and movement disorders. Pain Manag 2017;7:133-40.

23. Broseta J, Roldan P, Gonzalez-Darder J, Bordes V, BarciaSalorio JL. Chronic epidural dorsal column stimulation in the treatment of causalgia pain. Appl Neurophysiol 1982;45:190-4.

24. Kemler MA, De Vet HC, Barendse GA, Van Den Wildenberg FA, Van Kleef M. The effect of spinal cord stimulation in patients 
with chronic reflex sympathetic dystrophy: two years' followup of the randomized controlled trial. Ann Neurol 2004;55:138.

25. Kemler MA, de Vet HC, Barendse GA, van den Wildenberg FA, van Kleef M. Effect of spinal cord stimulation for chronic complex regional pain syndrome Type I: five-year final followup of patients in a randomized controlled trial. J Neurosurg 2008;108:292-8.

26. Kemler MA, Barendse GA, van Kleef M, de Vet HC, Rijks CP, Furnée CA, et al. Spinal cord stimulation in patients with chronic reflex sympathetic dystrophy. N Engl J Med 2000;343: 618-24.

27. Kemler MA, Raphael JH, Bentley A, Taylor RS. The costeffectiveness of spinal cord stimulation for complex regional pain syndrome. Value Health 2010;13:735-42.

28. Shamji MF, De Vos C, Sharan A. The advancing role of neuromodulation for the management of chronic treatmentrefractory pain. Neurosurgery 2017;80:S108-13.

29. Harke H, Gretenkort P, Ladleif HU, Koester P, Rahman S. Spinal cord stimulation in postherpetic neuralgia and in acute herpes zoster pain. Anesth Analg 2002;94:694-700.

30. Dong DS, Yu X, Wan CF, Liu Y, Zhao L, Xi Q, et al. Efficacy of short-term spinal cord stimulation in acute/subacute zosterrelated pain: a retrospective study. Pain Physician 2017;20: E633-45.

31. Turner JA, Loeser JD, Deyo RA, Sanders SB. Spinal cord stimulation for patients with failed back surgery syndrome or complex regional pain syndrome: a systematic review of effectiveness and complications. Pain 2004;108:137-47.

32. Eldabe S, Buchser E, Duarte RV. Complications of spinal cord stimulation and peripheral nerve stimulation techniques: a review of the literature. Pain Med 2016;17:325-36. 